\title{
Iron management in multicrystalline silicon through predictive simulation: point defects, precipitates, and structural defect interactions
}

\author{
Jasmin Hofstetter ${ }^{\mathrm{a}}$, David P. Fenning ${ }^{\mathrm{b}}$, Douglas M. Powell ${ }^{\mathrm{c}}$, \\ Ashley E. Morishige ${ }^{\mathrm{d}}$ and Tonio Buonassisi ${ }^{\mathrm{e}}$ \\ Massachusetts Institute of Technology, 77 Massachusetts Ave, Cambridge, MA 02139, USA \\ ajhofstet@mit.edu, bdpfenning@gmail.com, cdmpowell@alum.mit.edu, daemorish@mit.edu, \\ ebuonassisi@mit.edu
}

Keywords: silicon solar cells, gettering, interstitial iron, precipitated iron

\begin{abstract}
In multicrystalline silicon for photovoltaic applications, high concentrations of iron are usually found, which deteriorate material performance. Due to the limited solubility of iron in silicon, only a small fraction of the total iron concentration is present as interstitial solute atoms while the vast majority is present as iron silicide precipates. The concentration of iron interstitials can be effectively reduced during phosphorus diffusion gettering (PDG), but this strongly depends on the size and density of iron precipitates, which partly dissolve during high-temperature processing. The distribution of precipitated iron varies along the height of a mc-Si ingot and is not significantly reduced during standard PDG steps. However, the removal of both iron interstitials and precipitates can be enhanced by controlling their kinetics through carefully engineered time-temperature profiles, guided by simulations.
\end{abstract}

\section{Introduction}

To date, multicrystalline silicon ( $\mathrm{mc}-\mathrm{Si})$ is the preferred material for solar cell producers with a market share of more than 50\% in 2012 [1]. The main advantage of mc-Si over conventional monocrystalline $\mathrm{Si}$ ingot growth is the considerably lower production cost. However, in comparison to mono-Si, mc-Si wafers contain a higher density of crystalline defects, like dislocations and grain boundaries, and a higher concentration of metallic impurities. Iron is one of the most abundant metallic impurities, which, in combination with its electrical and kinetic properties, renders it one of the principal lifetime-limiting defects in many silicon materials [2,3]. In addition, the recombination-activity of other prominent defects in silicon like dislocations and oxide prepitates is strongly enhanced by iron decoration $[4,5]$

The as-grown concentration and distribution of iron strongly varies throughout mc-Si ingots. During ingot growth, only a small fraction of metallic impurity atoms segregates to the solidified crystal whereas the vast majority remains in the liquid fraction and is driven to the ingot top [6]. After silicon solidification, iron contained in the quartz crucible and crucible lining material diffuses into the solidified crystal and deteriorates the bottom and the border regions [7, 8]. Furthermore, after complete solidification, iron from the very top fraction that solidified last diffuses back into the ingot and deteriorates the upper part of the ingot [6]. As a result, iron concentrations of around $10^{13} \mathrm{~cm}^{-3}$ in the center and up to $10^{15} \mathrm{~cm}^{-3}$ in the top and border regions have been measured by inductively coupled plasma mass spectroscopy (ICP-MS) in commercial mc-Si ingots [8,9]. Iron concentrations up to $10^{16} \mathrm{~cm}^{-3}$ have also been found in silicon ribbon materials [2]. Iron concentration profiles from literature measured along the height of intentionally Fe-contaminated and commercial mc-Si ingots are plotted in Fig. 3(a). 


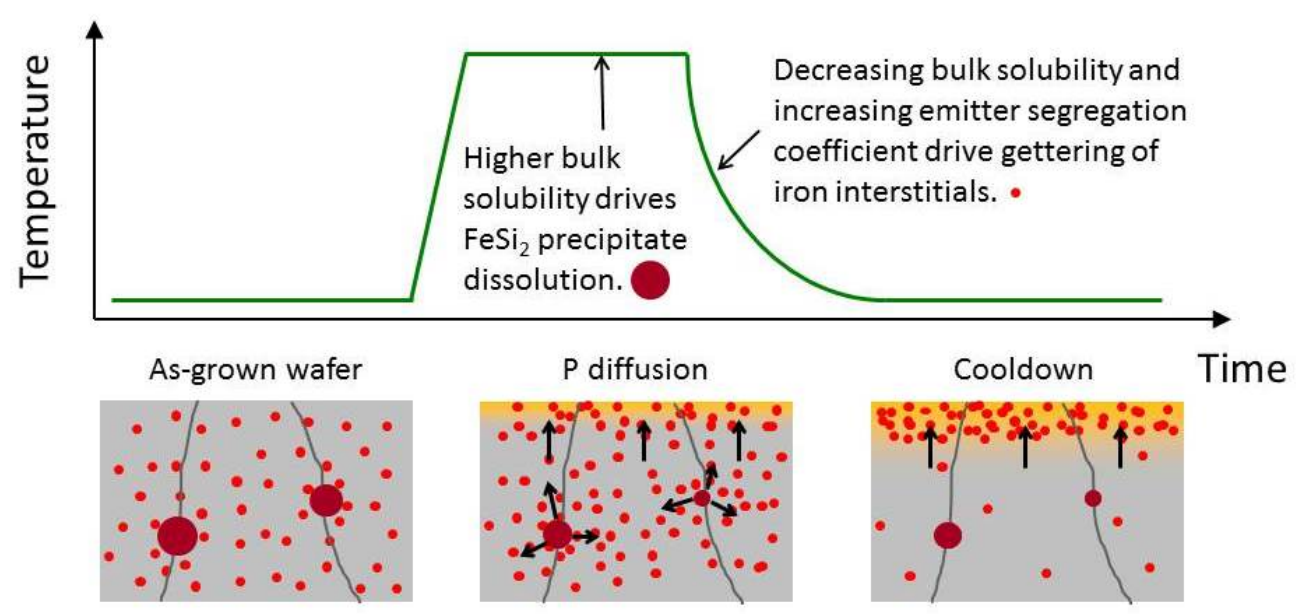

Fig. 1: Sketch of a cross-section of a mc-Si wafer containing iron interstitials and $\mathrm{FeSi}_{2}$ precipitates located along structural defects. The dissolution of precipitates and the diffusion of iron interstitials to the gettering layer during P diffusion and cool-down are indicated by arrows (adapted from [16]).

Due to its limited solid solubility, usually only $0.1-10 \%$ of iron is interstitially dissolved in the Si matrix while the rest is present in the form of second-phase precipitates, mainly $\beta$-iron silicide, $\beta-\mathrm{FeSi}_{2}[10]$. The small fraction of interstitially dissolved iron, $\mathrm{Fe}_{i}$, however, has a large detrimental effect on material performance and is the lifetime-limiting defect in most as-grown $p$-type mc$\mathrm{Si}$ wafers [11, 12]. Iron silicide precipitates have also been found to be recombination-active [13], but since they are present in a much lower density [14], their net effect on lifetime is usually much lower, in particular in cast mc-Si materials. However, due to the incomplete dissolution and removal of iron silicide precipitates during standard phosphorus diffusion gettering (PDG) [15], precipitated iron has a large indirect effect on lifetime forming an internal source of iron interstitials and increasing their concentration during high-temperature processing. A sketch of a mc-Si wafer cross section showing iron interstitials and precipitates along structural defects is shown in Fig. 1. A typical PDG time-temperature profile is also shown and the kinetics of iron interstitials and precipitates during processing is indicated by arrows.

In several different experiments $[15,17,18,19,20,21]$, the evolution of the interstitial iron concentration and of $\beta-\mathrm{FeSi}_{2}$ precipitates during different solar cell processing schemes has been measured by $\mathrm{Fe}_{i}-\mathrm{B}_{s}$ pair dissociation in combination with lifetime measurements [22] and synchrotronbased X-ray fluorescence microscopy $(\mu-\mathrm{XRF})$. Experimental trends have been compared to and predicted or confirmed by simulation results obtained with a semi-empirical 1D gettering model $[16,23,24,25]$. The development of different $\mathrm{P}$ diffusion and gettering models over the last two decades $[26,27,28,29,30,31,32]$ has recently culminated in the existence of very sophisticated 2 and 3D models and simulations that capture many details of the physics behind the complicated PDG process. Most experimental trends, however, are well-described by a faster, simpler 1D model which allows mapping of a large parameter space in a short time, necessary for process optimization. In this paper, we summarize our learnings and conclusions drawn from the different simulations and experiments to date. In combination with the revised solubility and diffusivity parameters of iron in silicon at lower temperatures $[33,34]$, these learnings shall enable the design of processing guidelines for the effective management of iron-related defects in different mc-Si during solar cell processing.

\section{Interstitial iron}

In most as-grown $p$-type silicon materials, up to $10^{13}$ atoms $/ \mathrm{cm}^{3}$ of iron are present in interstitially dissolved form, generally forming pairs with the $p$-type dopant atoms (e.g. $\mathrm{Fe}_{i}-\mathrm{B}_{s}$ pairs). As mentioned above, these dilute iron atoms only comprise a small fraction of the total iron concentration 


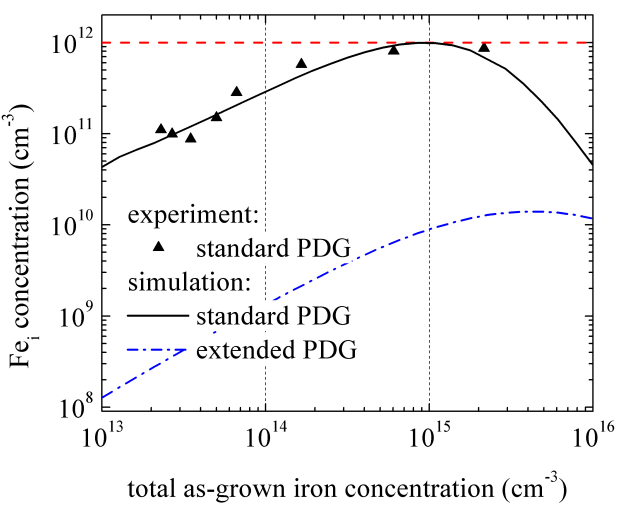

(a)

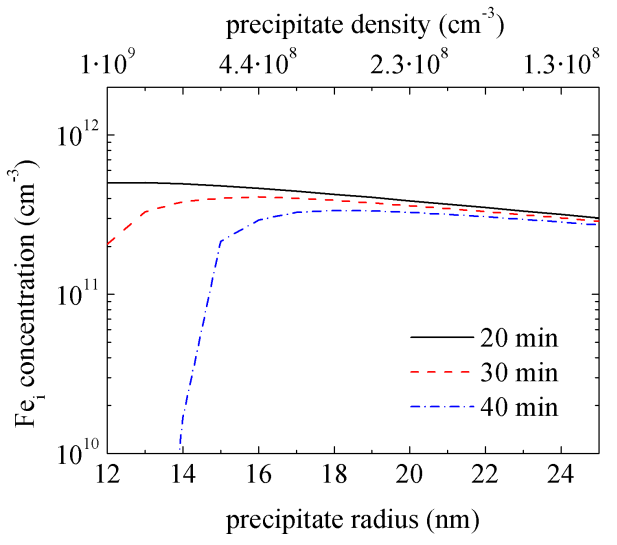

(b)

Fig. 2: (a) Simulated $\mathrm{Fe}_{i}$ concentration as a function of the total as-grown iron concentration: as-grown (dashed line) after standard PDG (solid line) and after extended PDG (dash-dotted line); triangles are experimental data points from [35]; (b) simulated $\mathrm{Fe}_{i}$ concentration after 20, 30, and 40 min PDG at $840{ }^{\circ} \mathrm{C}$ as a function of as-grown $\mathrm{FeSi}_{2}$ precipitate radius

in most materials, but due to their large capture cross section they are usually the principal electron lifetime-limiting defect. During PDG, the $\mathrm{Fe}_{i}$ concentration can be decreased, but its final value strongly depends on the density and size of iron silicide precipitates, which partly dissolve during high-temperature processing.

\section{Post-gettered interstitial iron as a function of the total iron concentration}

It has been observed experimentally that the $\mathrm{Fe}_{i}$ concentration in mc-Si samples taken from different heights of an intentionally iron-contaminated ingot decreases after standard PDG, but that the post-processed $\mathrm{Fe}_{i}$ concentration strongly increases toward the bottom and the top of the ingot [35]. Gettering simulations have shown that the $\mathrm{Fe}_{i}$ concentration after standard PDG strongly depends on the total concentration of iron [24], which, as mentioned above, is comprised of over $90 \% \mathrm{FeSi}_{2} \mathrm{pre}^{-}$ cipitates. In Fig. 2(a), the $\mathrm{Fe}_{i}$ concentration at several ingot heights after standard PDG as measured by Coletti et al. [35] is plotted as a function of the total iron concentration at the respective ingot heights. Also shown is the simulated $\mathrm{Fe}_{i}$ concentration after $15 \mathrm{~min} \mathrm{PDG}$ at $850{ }^{\circ} \mathrm{C}$ as a function of the total iron concentration. The as-grown $\mathrm{Fe}_{i}$ concentration at room temperature has little impact on the post-gettered $\mathrm{Fe}_{i}$ concentration in the presence of precipitated iron since it immediately increases with increasing solid solubility when going to higher temperature. Therefore, for all the simulations, we assumed that $10^{12}$ iron atoms $/ \mathrm{cm}^{3}$ were present in interstitially dissolved form in the as-grown wafer while the rest of iron was homogeneously distributed on spherical $\mathrm{FeSi}_{2}$ precipitates of $25 \mathrm{~nm}$ radius, approximately corresponding to the largest precipitates that had been found in this material [15]. Both experimental and simulation results show that the post-gettered $\mathrm{Fe}_{i}$ concentration increases with increasing total iron concentration up to $10^{15} \mathrm{~cm}^{-3}$. For total iron concentrations $\gtrsim 10^{15} \mathrm{~cm}^{-3}$, the simulation suggests that the $\mathrm{Fe}_{i}$ concentration decreases due to enhanced re-precipitation of interstitial iron during cooldown in the presence of a high precipitate density.

Also shown is the simulated $\mathrm{Fe}_{i}$ concentration as a function of the total iron concentration for an extended PDG step when the $15 \mathrm{~min} P$ diffusion at $850{ }^{\circ} \mathrm{C}$ is followed by a slow exponential cool down to room temperature at a time constant of $210 \mathrm{~min}$. The simulated curve suggests that the $\mathrm{Fe}_{i}$ concentration is decreased below $10^{10} \mathrm{~cm}^{-3}$ for all total iron concentrations. It has been shown by different groups than such an extended PDG can achieve much lower $\mathrm{Fe}_{i}$ concentrations than the standard PDG $[17,36,37,38,39,40]$. Recent experimental results confirm that such low $\mathrm{Fe}_{i}$ concentrations can be systematically achieved over a large range of total iron concentrations up to $10^{15} \mathrm{~cm}^{-3}$ [41]. 


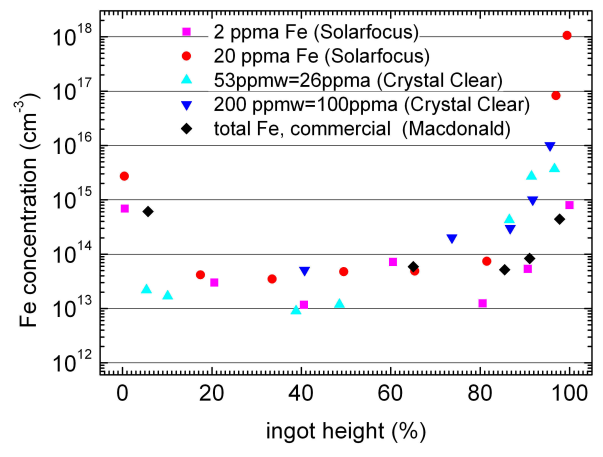

(a)

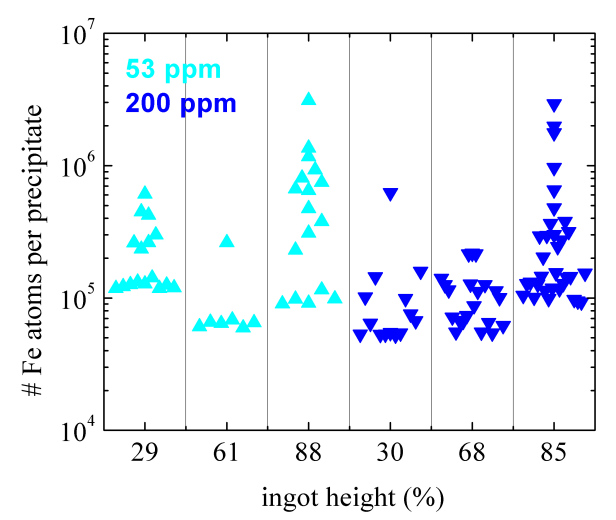

(b)

Fig. 3: (a) Total Fe concentration measured by ICP-MS along the height of several mc-Si ingots grown from intentionally Fe-contaminated melt and along one non-contaminated ingot (black diamonds) $[6,9,44]$; (b) number of Fe atoms per precipitate measured by $\mu$-XRF along the 53 and 200 ppmw ingot from [6] (adapted from [15]); each data point represents one precipitate measured.

Post-gettered interstitial iron as a function of the precipitate size As first pointed out by Plekhanov et al. [42], the post-gettered $\mathrm{Fe}_{i}$ concentration depends not only on the total iron concentration, but also on the average size and density of iron silicide precipitates [20]. Fig. 2(b) shows the simulated $\mathrm{Fe}_{i}$ concentration after PDG at $840^{[0]} \mathrm{C}$ as a function of the precipitate radius for different high-temperature plateau times of 20,30, and 40 min. Simulations suggest that the post-gettered $\mathrm{Fe}_{i}$ concentration strongly depends on the precipitate radius, especially for longer plateau times. Experimental results of $\mathrm{Fe}_{i}$ concentrations measured confirm the simulated trend. Three mc-Si sister wafers were subjected to different pre-annealing treatments before PDG to engineer the precipitate size distribution [20]. The trend of decreasing post-gettered $\mathrm{Fe}_{i}$ concentration with presumably decreasing precipitate radius was observed after a 40 min PDG process at $840{ }^{\circ} \mathrm{C}$.

Simulations and experiments suggest that smaller as-grown precipitates allow for a faster dissolution due to a higher surface energy and a larger interface area, providing a situation where gettering is limited by the diffusion of iron interstitials rather than by the dissolution of $\mathrm{FeSi}_{2}$ precipitates. In this diffusion-limited case, larger amounts of iron can be gettered in a given time and the potential exists for nearly complete iron removal during gettering, e.g., in ribbon materials. However, the post-processed $\mathrm{Fe}_{i}$ concentration strongly depends on the plateau time of PDG, which has to be long enough so that all dissolved iron can diffuse to the P-diffused gettering layer. In the dissolution-limited case, only small total amounts of iron are getterable in a reasonable process time and the $\mathrm{Fe}_{i}$ concentration is relative insensitive to the plateau time during standard PDG. Larger precipitates dissolve more slowly and gettering is limited by precipitate dissolution. In this case, longer plateau times do not considerably increase gettering efficacy, as also confirmed by experimental results [43].

\section{Precipitated iron}

As mentioned in previous sections, more than $90 \%$ of the total iron concentration in as-grown mc$\mathrm{Si}$ is present in form of $\mathrm{FeSi}_{2}$ precipitates. Precipitates themselves are recombination-active [13] and therefore decrease minority carrier lifetime. However, they are usually present in a much lower density than iron interstitials in cast $\mathrm{mc}-\mathrm{Si}$, and therefore represent a much lower density of recombination centers. Such precipitates found by $\mu$-XRF measurements typically consist of about $10^{4} \mathrm{~cm}^{-3}$ up to $10^{7} \mathrm{~cm}^{-3}$ iron atoms in cast mc-Si where the lower bound is determined by the detection limit of the method. For a total iron concentration of $10^{14} \mathrm{~cm}^{-3}$, these measured precipitate sizes result in precipitate density between $10^{7} \mathrm{~cm}^{-3}$ and $10^{10} \mathrm{~cm}^{-3}$. 
Despite having a lower direct impact on minority carrier lifetime, $\mathrm{FeSi}_{2}$ precipitates are indirectly detrimental to material performance when they dissolve during high-temperature processing steps and therefore increase the concentration of recombination-active iron interstitials. Therefore, the amount and distribution of precipitated iron has to be taken into account when high-temperature steps during the solar cell process are optimized for different types of Si materials.

As-grown precipitate distribution To investigate the as-grown precipitate distribution (size and density) as a function of the total iron concentration, spatially resolved $\mu$-XRF measurements have been performed at three different heights of two intentionally Fe-contaminated ingots ( 53 and 200 ppmw Fe in the melt) $[15,35]$. As an example, the $\mu$-XRF map measured on an as-grown sample from $88 \%$ height of the 53 ppmw ingot is shown in Fig. 4(a).

The number of Fe atoms/precipitate of all detected precipitates is plotted in Fig. 3(b) as a function of ingot height. A higher precipitate density was found at the top in comparison to the center and bottom of the ingot, i.e., the density increases with increasing total iron concentration (compare to Fig. 3(a)). Similar but slightly increasing average precipitate sizes were also found with increasing total iron concentration.

Precipitate distribution after standard gettering Generally, the concentration of transition metal impurities in the wafer bulk is believed to be effectively reduced during PDG, which generally translates into an increase in minority carrier lifetime. This lifetime improvement, however, is mainly achieved through the reduction of dissolved metal impurities in the wafer bulk. It has been observed experimentally that the $\mathrm{Fe}_{i}$ reduction and lifetime improvement can be offset during subsequent hightemperature processes, e.g. firing for contact formation $[19,45]$. As mentioned previously, simulations show that, depending on the process temperature, gettering may be limited by the dissolution of $\mathrm{FeSi}_{2}$ precipitates and large amounts of iron may remain in the material after gettering in precipitated form $[23,24]$. These remaining precipitates further dissolve during subsequent high-temperature steps, increasing the concentration of iron interstitials, and leading to the observed re-degradation of carrier lifetime.

To confirm simulation results experimentally, the size and density of $\mathrm{FeSi}_{2}$ precipitates after PDG were measured by $\mu$-XRF on wafers taken from the three heights of the two intentionally Fe- contaminated ingots. The P - gettered wafers were sister wafers to the as-grown ones mentioned in the previous section. The $\mu$-XRF map recorded at $88 \%$ height of the 53 ppmw ingot after standard PDG is shown in Fig. 4(b). A very similar density and size of $\mathrm{FeSi}_{2}$ precipitates has been found in all getttered samples after standard PDG in comparison to the as-grown sister samples. This means that most precipitates cannot be dissolved and only a very small fraction of total iron is removed from the wafer bulk during standard PDG. Finally, a $\mu$-XRF map was recorded on a third sister sample from $88 \%$ height of the 53 ppmw ingot after standard PDG followed by a faux-firing step in the absence of metal contacts (Fig. 4(c)). Again, a similar size and density of $\mathrm{FeSi}_{2}$ precipitates is observed as in the asgrown and gettered sister wafers, meaning that the precipitated iron is not significantly altered during the contact-firing step either.

Precipitate distribution after alternative gettering In another experiment, the impact of standard PDG and low temperature annealing (LTA) steps on the precipitate distribution was investigated in the highly iron-contaminated "red zone" of a commercial mc-Si ingot close to the crucible wall [18]. Consistent with results obtained at different ingot heights on the intentionally contaminated ingots, the precipitate size and density in the "red zone" was found not to change significantly neither after standard PDG nor after an LTA step [40].

However, very recently, a significant reduction of precipitated iron was observed after PDG at higher plateau temperatures up to $1000{ }^{\circ} \mathrm{C}[21,46]$. In [21], enhanced reductions in precipitate iron were also observed when introducing a high-temperature peak before the actual PDG step at standard plateau temperature. 


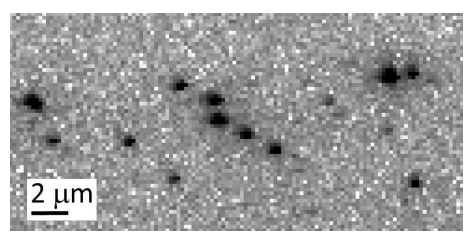

(a) As-grown

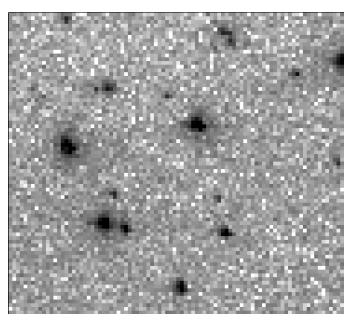

(b) After standard PDG

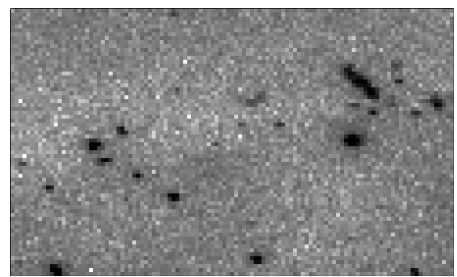

(c) After PDG and firing

Fig. 4: $\mu$-XRF maps along a grain boundary in three mc-Si sister wafers from the top of the intentionally 53 ppmw Fe-contaminated ingot showing the presence of $\mathrm{FeSi}_{2}$ precipitates of similar size and density at different steps in the solar cell process; pixel size is $200 \times 200 \mathrm{~nm}$ (adapted from [15]).

Finally, the impact of continuously ramping PDG profiles on the final iron distribution and lifetime has been studied. Instead of keeping a constant temperature plateau during PDG, the temperature is ramped up to a high peak temperature and then immediately ramped down again. Compared to a standard process, simulations predict that such a continuously ramping profile more effectively reduces both precipitated and interstitial iron while keeping the same sheet resistance and process time [47]. First experimental results indicate that both processes are equally effective at reducing the $\mathrm{Fe}_{i}$ concentration and increase lifetime [48]. The impact on the concentration of precipitated iron is subject to further studies.

\section{Interaction of metals with structural defects}

In addition to iron interstitials, dislocations are one of the principal lifetime-limiting defects in mc-Si for solar cells. While the recombination at iron interstitials is generally well-described by the ShockleyRead-Hall model, the existing models to quantify the impact of the dislocation density on charge carrier lifetime $[49,50]$ include the background lifetime in the dislocation-free semiconductor and the so-called recombination strength of dislocations as fit parameters. The recombination strength of dislocations was found to vary among different dislocation clusters [51] and nano-XRF studies have shown that a higher recombination activity seems to be correlated with metal decoration [52].

We have recently hypothesized that the recombination strength of dislocations may be correlated with the $\mathrm{Fe}_{i}$ concentration in their vicinity in P-gettered mc-Si wafers [53]. A direct correlation between the spatially varying dislocation density and $\mathrm{Fe}_{i}$ concentration in mc-Si has been observed before [50,54]. An experimental investigation of the spatially resolved electron lifetime as a function of measured $\mathrm{Fe}_{i}$ concentration and dislocation density to quantify this correlation is ongoing. First results, as shown in Fig. 5 show that dislocation clusters showing lower lifetime are correlated with higher concentration of $\mathrm{Fe}_{i}$ (region A) while dislocation clusters showing higher lifetime are correlated with a lower $\mathrm{Fe}_{i}$ concentration (region $\mathrm{B}$ ).

In a parallel experiment detailed in $[43,55]$, the $\mathrm{Fe}_{i}$ concentration in highly dislocated areas has been observed to increase systematically with increasing PDG plateau temperature. Dislocations represent favorable nucleation sites for second-phase particles [56], e.g., $\mathrm{FeSi}_{2}$ precipitates, which likely exist in a higher density in highly dislocated regions. The observed increase of the $\mathrm{Fe}_{i}$ concentration in highly dislocated regions is therefore well-explained by an enhanced dissolution of $\mathrm{FeSi}_{2}$ particles during higher temperature processing.

Lastly, it has been observed in recent experiments that the interaction between dislocations and impurity atoms during gettering seems to be reciprocal: On the one hand, the strain field around dislocations and their provision of heterogeneous nucleation sites favor segregation of impurity atoms and the nucleation of second phase particles and impede their effective removal during standard PDG. 

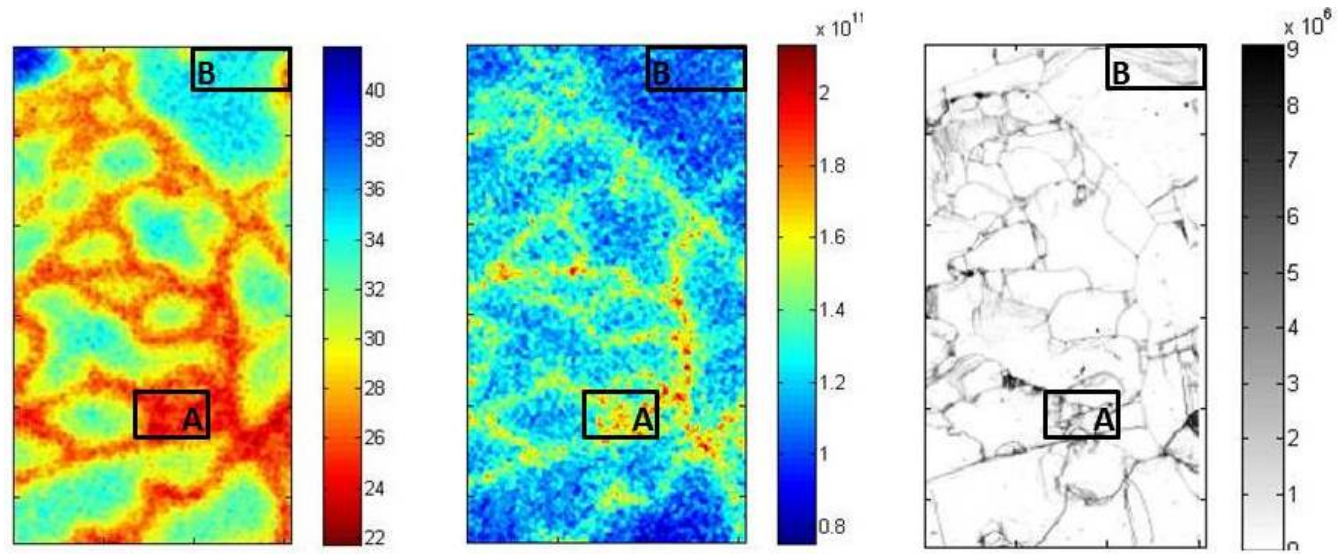

Fig. 5: Calibrated photoluminescence images of the electron lifetime ( $\mu \mathrm{s}), \mathrm{Fe}_{i}$ concentration $\left(\mathrm{cm}^{-3}\right)$ and dislocation density map $\left(\mathrm{cm}^{-3}\right)$ calculated from etch pit counting in a mc-Si wafer after standard PDG; dislocation cluster in region A shows a lower lifetimes correlated with higher concentration of $\mathrm{Fe}_{i}$ while dislocation cluster $\mathrm{B}$ shows higher lifetime and a low $\mathrm{Fe}_{i}$ concentration

On the other hand, the apparent density of dislocations (etch pits) has been observed to decrease after PDG in several experiments [55, 57], suggesting that the dissolution and gettering of metallic impurities during PDG may have an impact on dislocation kinetics even at relatively low temperatures.

\section{Conclusions}

We reviewed the role of iron-related defects in silicon, iron interstitials and iron silicide precipitates, during standard and alternative $\mathrm{P}$ gettering processes and their respective impact on material performance. Their interaction with dislocations has also been briefly discussed. While the efficacy of standard PDG processes to reduce iron interstitials strongly depends on the precipitated iron concentration and distribution, they usually fail to significantly reduce the concentration of precipitated iron in mc-Si wafers. Alternative gettering processes with tailored time-temperature profiles guided by simulation, however, have shown the potential to decrease the overall concentration of interstitial and precipitated iron in mc-Si materials. Nevertheless, the effective "cleaning" of dislocations from decorating metals is still a topic of active investigation. The complete removal of precipitated and interstitial iron by a combination of higher-temperature PDG plateau followed by a slow cool down or low temperature annealing may bear the potential to increase carrier lifetimes in highly dislocated areas.

\section{References}

[1] P. Mints, SPV market research, the global market for pv technologies, in: 9th Photovoltaic Science Application and Technology Conference and Exhibition, 2012.

[2] A. A. Istratov, T. Buonassisi, R. J. McDonald, A. R. Smith, R. Schindler, J. A. Rand, J. P. Kalejs, E. R. Weber, Metal content of multicrystalline silicon for solar cells and its impact on minority carrier diffusion length, J. Appl. Phys. 94 (2003) 6552--6559.

[3] T. Buonassisi, A. A. Istratov, M. D. Pickett, M. Heuer, J. P. Kalejs, G. Hahn, M. A. Marcus, B. Lai, Z. Cai, S. M. Heald, T. F. Ciszek, R. F. Clark, D. W. Cunningham, A. M. Cabor, R. Jonczyk, S. Narayanan, E. Sauar, E. R. Weber, Chemical natures and distributions of metal impurities in multicrystalline silicon materials, Prog. Photovoltaics res. appl. 14 (2006) 513--531.

[4] V. Kveder, M. Kittler, W. Schroter, Recombination activity of contaminated dislocations in silicon: a model describing electron-beam-induced current contrast behavior, Phys. Rev. B 63 (2001) 115208. 
[5] J. Murphy, K. Bothe, V. Voronkov, R. Falster, On the mechanism of recombination at oxide precipitates in silicon, Appl. Phys. Lett. 102 (4) (2013) 042105.

[6] R. Kvande, B. Geerligs, G. Coletti, L. Arnberg, M. D. Sabatino, E. J. Ovrelid, C. C. Swanson, Distribution of iron in multi-crystalline silicon ingots, J. Appl. Phys. 104 (2008) 064905.

[7] E. Olsen, E. Øvrelid, Silicon nitride coating and crucible effects of using upgraded materials in the casting of multicrystalline silicon ingots, Prog. Photovoltaics res. appl. 16 (2) (2008) 93--100.

[8] T. U. Nerland, L. Arnberg, A. Holt, Origin of the low carrier lifetime edge zone in multicrystalline pv silicon, Prog. Photovoltaics res. appl. 17 (2008) 289 -- 296.

[9] D. Macdonald, A. Cuevas, A. Kinomura, Y. Nakano, L. J. Geerligs, Transition-metal profiles in a multicrystalline silicon ingot, J. Appl. Phys. 97 (2005) 033523--1 -- 033523--7.

[10] T. Buonassisi, A. A. Istratov, M. Heuer, M. A. Marcus, R. Jonczyk, J. Isenberg, B. Lai, Z. Cai, S. Heald, W. Warta, R. Schindler, G. Willeke, E. R. Weber, Synchrotron-based investigations of the nature and impact of iron contamination in multicrystalline silicon solar cells, J. Appl. Phys. 97 (2005) 074901--1 -11.

[11] B. L. Sopori, L. Jastrzebski, T. Tan, A comparison of gettering in single-and multicrystalline silicon for solar cells, in: Proc. 25th IEEE PVSC, Washington, D.C., 1996, p. 625.

[12] S. Rein, S. W. Glunz, Electronic properties of interstitial iron and iron-boron pairs determined by means of advanced lifetime spectroscopy, J. Appl. Phys. 98 (2005) 113711.

[13] P. Gundel, M. C. Schubert, F. D. Heinz, W. Kwapil, W. Warta, G. Martinez-Criado, M. Reiche, E. R. Weber, Impact of stress on the recombination at metal precipitates in silicon, J. Appl. Phys. 108 (10) (2010) 103707.

[14] T. Buonassisi, A. Istratov, M. Marcus, B. Lai, Z. Cai, S. Heald, E. Weber, Engineering metal-impurity nanodefects for low-cost solar cells, Nat. Mater. 4 (2005) 676--679.

[15] D. P. Fenning, J. Hofstetter, M. I. Bertoni, G. Coletti, B. Lai, C. del Canizo, T. Buonassisi, Precipitated iron: A limit on gettering efficacy in multicrystalline silicon, J. Appl. Phys. 113 (4) (2013) 044521.

[16] D. M. Powell, D. P. Fenning, J. Hofstetter, J. F. Lelievre, C. d. Canizo, T. Buonassisi, TCAD for PV - a fast method to accurately model metal impurity evolution during solar cell processing, PV International 15 (2012) 91.

[17] J. Hofstetter, J. F. Leliévre, C. del Cañizo, A. Luque, Study of internal versus external gettering of iron during slow cooling processes for silicon solar cell fabrication, Solid State Phenomena 156-158 (2010) 387--393.

[18] D. P. Fenning, J. Hofstetter, M. I. Bertoni, S. Hudelson, M. Rinio, J. F. Lelièvre, B. Lai, C. del Cañizo, T. Buonassisi, Iron distribution in silicon after solar cell processing: Synchrotron analysis and predictive modeling, Appl. Phys. Lett. 98 (2011) 162103.

[19] J.-F. Lelievre, J. Hofstetter, A. Peral, I. Hocesc, F. Recart, C. del Canizo, Dissolution and gettering of iron during contact co-firing, Energy Procedia 8 (2011) 257 -- 262.

[20] J. Hofstetter, D. P. Fenning, J.-F. Lelièvre, C. del Cañizo, T. Buonassisi, Engineering metal precipitate size distributions to enhance gettering in multicrystalline silicon, phys. stat. sol. (a) 209 (10) (2012) 1861-1865 .

[21] D. P. Fenning, A. S. Zuschlag, M. I. Bertoni, B. Lai, G. Hahn, T. Buonassisi, Improved iron gettering of contaminated multicrystalline silicon by high-temperature phosphorus diffusion, J. Appl. Phys. 113 (2013) 214504. 
[22] D. H. Macdonald, L. J. Geerligs, A. Azzizi, Iron detection in crystalline silicon by carrier lifetime measurements for arbitrary injection and doping, J. Appl. Phys. 95 (3) (2004) 1021--1028.

[23] J. Hofstetter, D. P. Fenning, M. I. Bertoni, J. F. Lelièvre, C. del Cañizo, T. Buonassisi, Impurity-toefficiency simulator: Predictive simulation of silicon solar cell performance based on iron content and distribution, Prog. Photovoltaics Res. Appl. 19 (2010) 487 -- 497.

[24] J. Hofstetter, J. F. Lelièvre, D. P. Fenning, M. I. Bertoni, T. Buonassisi, C. del Cañizo, Towards the tailoring of $\mathrm{p}$ diffusion gettering to as-grown silicon material properties, Solid State Phenomena 178 (2011) $158--165$.

[25] Impurities-to-Efficiency (I2E) simulator, online applet, http://pv-i2e.mit.edu.

[26] H. Hieslmair, S. Balasubramanian, A. A. Istratov, E. R. Weber, Gettering simulator: physical basis and algorithm, Semiconductor Science and Technology 16 (2001) 567--574.

[27] C. del Canizo, A. Luque, A comprehensive model for the gettering of lifetime-killing impurities in silicon, J. Electrochem. Soc. 147 (2000) 2685--2692.

[28] M. Seibt, A. Sattler, C. Rudolf, O. Voss, V. Kveder, W. Schroter, Gettering in silicon photovoltaics: current state and future perspectives, phys. stat. sol. (a) 203 (2006) 696.

[29] A. Bentzen, A. Holt, R. Kopecek, G. Stokkan, J. S. Christensen, B. G. Svensson, Gettering of transition metal impurities during phosphorus emitter diffusion in multicrystalline silicon solar cell processing, J. Appl. Phys. 99 (2006) 093509.

[30] A. Haarahiltunen, H. Vainola, O. Anttila, E. Saarnilehto, M. Yli-Koski, J. Storgards, J. Sinkkonen, Modeling of heterogeneous precipitation of iron in silicon, Appl. Phys. Lett. 87 (2005) 151908.

[31] J. Schon, H. Habenicht, M. C. Schubert, W. Warta, Understanding the distribution of iron in multicrystalline silicon after emitter formation: Theoretical model and experiments, J. Appl. Phys. 109 (6) (2011) 063717.

[32] R. Chen, H. Wagner, A. Dastgheib-Shirazi, M. Kessler, Z. Zhu, V. Shutthanandan, P. P. Altermatt, S. T. Dunham, A model for phosphosilicate glass deposition via pocl 3 for control of phosphorus dose in si, J. Appl. Phys. 112 (12) (2012) 124912.

[33] J. D. Murphy, R. J. Falster, http://dx.doi.org/10.1002/pssr.201105388Contamination of silicon by iron at temperatures below $800^{\circ} \mathrm{c}$, phys. stat. sol. RRL $5(10-11)$ (2011) 370--372. http://dx.doi.org/10.1002/pssr.201105388 doi:10.1002/pssr.201105388. http://dx.doi.org/10.1002/pssr.201105388

[34] J. D. Murphy, R. J. Falster, The relaxation behaviour of supersaturated iron in single-crystal silicon at 500 to $750^{0}$ c, J. Appl. Phys. 112 (11) (2012) 113506.

[35] G. Coletti, R. Kvande, V. D. Mihailetchi, L. J. Geerligs, L. Arnberg, E. J. Ovrelid, Effect of iron in silicon feedstock on p- and n-type multicrystalline silicon solar cells, J. Appl. Phys. 104 (2008) 104913.

[36] J. Harkonen, V.-P. Lempinen, T. Juvonen, J. Kylmaluoma, Recovery of minority carrier lifetime in lowcost multicrystalline silicon, Sol. Energ. Mat. Sol. Cells 73 (2003) 125--130.

[37] P. Manshanden, L. Geerligs, Improved phosphorous gettering of multicrystalline silicon, Sol. Energy Mater. Sol. Cells 90 (2006) 998--1012.

[38] J. Tan, A. Cuevas, D. Macdonald, N. Bennett, I. Romijn, T. Trupke, R. Bardos, Optimised gettering and hydrogenation of multi-crystalline silicon wafers for use in solar cells, in: Proc. 22nd EUPVSEC, Milan, Italy, 2007, pp. 1309--1313. 
[39] M. D. Pickett, T. Buonassisi, Iron point defect reduction in multicrystalline silicon solar cells, Appl. Phys. Lett. 92 (2008) 122103.

[40] M. Rinio, A. Yodyunyong, S. Keipert-Colberg, Y. P. B. Mouafi, D. Borchert, A. Montesdeoca-Santana, Improvement of multicrystalline silicon solar cells by a low temperature anneal after emitter diffusion, Prog. Photovoltaics Res. Appl. 19 (2010) 165 -- 169. doi:10.1002/pip. 1002.

[41] J. Hofstetter, D. P. Fenning, T. Buonassisi, Toward customizing the solar cell process to as-grown silicon material properties, unpublished.

[42] P. Plekhanov, R. Gafiteanu, U. Gösele, T. Tan, Modeling of gettering of precipitated impurities from si for carrier lifetime improvement in solar cell applications, J. Appl. Phys. 86 (1999) 2453--2458.

[43] D. P. Fenning, High temperature defect engineering for silicon solar cells: Predictive process simulation and synchrotron-based microcharacterization, Ph.D. thesis, Massachusetts Institute of Technology (2013).

[44] I. E. Reis, S. Riepe, W. Koch, J. Bauer, S. Beljakowa, O. Breitenstein, H. Habenicht, D. Kresner-Kiel, G. Pensl, J. Schon, W. Seifert, Effect of impurities on solar cell parameters in intentionally contaminated multicrystalline silicon, in: proc. 24th EUPVSEC, Hamburg, Germany, 2009, pp. 2144 -- 2148.

[45] B. Michl, J. Schon, W. Warta, M. C. Schubert, The impact of different diffusion temperature profiles on iron concentrations and carrier lifetimes in multicrystalline silicon wafers, IEEE J. Photovoltaics 3 (2012) $635-640$.

[46] D. Macdonald, S. Phang, F. Rougieux, S. Lim, D. Paterson, D. Howard, M. D. de Jonge, C. Ryan, Ironrich particles in heavily contaminated multicrystalline silicon wafers and their response to phosphorus gettering, Semiconductor Science and Technology 27 (12) (2012) 125016.

[47] A. E. Morishige, D. P. Fenning, J. Hofstetter, D. M. Powell, T. Buonassisi, Enhanced phosphorus diffusion gettering by temperature optimization, in: 38th IEEE PVSC, Austin, TX, 2012.

[48] A. E. Morishige, Master's thesis (unpublished).

[49] C. Donolato, Modeling the effect of dislocations on the minority carrier diffusion length of a semiconductor, J. Appl. Phys. 84 (5) (1998) 2656--2664.

[50] G. Stokkan, S. Riepe, O. Lohne, W. Warta, Spatially resolved modeling of the combined effect of dislocations and grain boundaries on minority carrier lifetime in multicrystalline silicon, J. Appl. Phys. 101 (5) (2007) 053515.

[51] M. Rinio, S. Peters, M. Werner, A. Lawerenz, H. Muller, Measurement of the normalized recombination strength of dislocations in multicrystalline silicon solar cells, in: Solid State Phenomena 82 -- 84, 2002, pp. 701--706.

[52] M. I. Bertoni, D. P. Fenning, M. Rinio, V. Rose, M. Holt, J. Maser, T. Buonassisi, Nanoprobe X-ray fluorescence characterization of defects in large-area solar cells, Energy \& Environmental Science 4 (10) (2011) 4252--4257.

[53] J. Hofstetter, D. P. Fenning, D. B. Needleman, D. M. Powell, A. E. Morishige, S. Castellanos, T. Buonassisi, Correlation of the interstitial iron concentration and the recombination strength of dislocations in multicrystalline silicon, in: visual presentation at SiliconPV 2013, Hameln, Germany, 2013.

[54] C. Reimann, G. Müller, J. Friedrich, K. Lauer, A. Simonis, H. Wätzig, S. Krehan, R. Hartmann, A. Kruse, Systematic characterization of multi-crystalline silicon string ribbon wafer, Journal of Crystal Growth 361 (2012) 38 -- 43. 
[55] D. P. Fenning, A. S. Zuschlag, A. Frey, J. Hofstetter, M. I. Bertoni, G. Hahn, T. Buonassisi, Investigation of lifetime-limiting defects after high-temperature phosphorus diffusion in silicon solar cell materials, IEEE J. Photovoltaics (2013) submitted.

[56] M. Seibt, R. Khalil, V. Kveder, W. Schroter, Electronic states at dislocations and metal silicide precipitates in crystalline silicon and their role in solar cell materials, Appl. Phys. A 96 (2009) 235--253.

[57] H. J. Choi, M. I. Bertoni, J. Hofstetter, D. P. Fenning, D. M. Powell, S. Castellanos, T. Buonassisi, Dislocation density reduction during impurity gettering in multicrystalline silicon, IEEE J. Photovoltaics 3 (2012) 189 -- 198. 
Gettering and Defect Engineering in Semiconductor Technology XV

10.4028/www.scientific.net/SSP.205-206

Iron Management in Multicrystalline Silicon through Predictive Simulation: Point Defects, Precipitates, and Structural Defect Interactions

10.4028/www.scientific.net/SSP.205-206.15 